\title{
Shortwave Radiation and Sea Surface Temperature Variations over East and West Tropical Pacific Ocean
}

\author{
Yongxin Huang, Biyun Guo, Mantravadi Venkata Subrahmanyam* \\ School of Marine Science and Technology, Zhejiang Ocean University, Zhoushan, China \\ Email: *mvsm.au@gmail.com
}

How to cite this paper: Huang, Y.X., Guo, B.Y. and Subrahmanyam, M.V. (2018) Shortwave Radiation and Sea Surface Temperature Variations over East and West Tropical Pacific Ocean. Open Access Library Journal, 5: e4839.

https://doi.org/10.4236/oalib.1104839

Received: August 15, 2018

Accepted: August 26, 2018

Published: August 29, 2018

Copyright ( 2018 by authors and Open Access Library Inc.

This work is licensed under the Creative Commons Attribution International License (CC BY 4.0).

http://creativecommons.org/licenses/by/4.0/

\begin{abstract}
Shortwave radiation (SWR) is having direct impact on sea surface temperature (SST). In this paper the relation between SWR and SST has been over east and west Pacific Ocean. TAO/TRITON buoy data have been used for this study. It is well known that El Nino phenomenon is related to SST anomalies and warmer temperatures can observe over eastern Pacific Ocean (EP) leading to strong El Nino. The relation between eastern and western Pacific Ocean (WP) SST, SWR has been checked and presented. Monthly data have been used to find out the relation and the annual variation of SWR and SST during the El Nino and La Nina events are discussed.
\end{abstract}

\section{Subject Areas}

Atmospheric Sciences, Oceanology

\section{Keywords}

Shortwave Radiation, SST, El Nino, East Pacific Ocean, West Pacific Ocean

\section{Introduction}

Observations, analysis and model data are confirmed that global climate gradually warming since end of 19th century. The tropical Pacific Ocean area is the most significant region and broadest area for air-sea coupling phenomenon. The tropical Pacific is investigated in relation to global warming response which is beneficial to deepen not only the understanding of air sea coupled physical process, but also teleconnections such as El Nino which influences the global climate.

The basic characteristics of the El Nino phenomenon is sea surface tempera- 
ture (SST) abnormally elevated in the east Pacific Ocean (EP) coast, sea level rise, and leads to a stream that flows south. Under normal conditions, west $\mathrm{Pa}$ cific Ocean (WP) characterized by warm SST and cold SST in the east leads to easterly trade winds in the lower atmosphere over the equatorial Pacific Ocean (Walker circulation). To improve our understanding of ENSO evolution, different atmospheric and ocean properties are essential to measure. ENSO phenomenon has been studied by the using some of the ocean or atmospheric parameters for constructing an index to describe the phase and strength of ENSO events [1].

Several different indices mostly based on SST. The SST anomalies are used to obtain the indices over the specified ocean region [2] [3]. The surface over the tropical and subtropical Pacific Ocean radiative energy balance associated with the spatial and temporal variability leads to ENSO events resulting droughts in some areas and heavy precipitation other areas.

The Earth and ocean's climate system is driven by the radiative energy balance and mainly by solar shortwave radiation (SWR). SST is directly depends on the radiation coming from the sun. SST has always been an important research area in the field of marine science. SST is the combined result of interaction between the atmosphere and ocean thermal and dynamic process. Seasonal, interannual and longer term variations are important for climate change systems. Warm pool persists continuously over western pacific; however over eastern pacific surface temperatures vary due to global circulation pattern. Southern oscillation index (SOI) alters the atmospheric circulation pattern.

The SST is sensitive to the solar radiation attenuation depth [4] [5] [6] [7] [8]. SST to the solar attenuation depth in the warm pool is having strong sensitivity to intraseasonal [9]. As it is well known that, SST is playing a major role in altering global circulation. Over the tropics due to SWR surplus is energy available. If the warming of SST happens the circulation over the equatorial region will alter (Walker circulation), affecting the precipitation pattern over the globe.

In order to study SST variations due to SWR, we used the SWR and SST data to understand the relation between them. How shortwave radiation is impacting SST over east and western Pacific. Monthly and annual variation of SST over EP and WP studied in relation with shortwave radiation. The variations of SWR and SST during El Nino and La Nina events are presented.

\section{Data}

TAO/TRITON buoys measure oceanographic and surface meteorological data. We obtained the SWR from the buoy data; SWR-measured at 3.5 meters above the sea surface; SST - sea surface temperature measured at 1 meter below the sea surface; Daily - average of hourly or higher resolution data collected each day (hourly). Monthly average of all the data collected during each month. A minimum of 15 daily values are required to compute a monthly average.

We selected area in the eastern and western, southern and northern parts of 
the tropical Pacific to obtain data at located in $8^{\circ} \mathrm{S}-8^{\circ} \mathrm{N} 147^{\circ} \mathrm{E}$ in the WP and $8^{\circ} \mathrm{S}-8^{\circ} \mathrm{N} ; 95^{\circ} \mathrm{W}$ in the EP. We can compare the difference between the SST and SW in the EP and WP. Using the available daily, monthly data we analyzed the relation between SWR and SST for the period from November 1998 to September 2003. Annual values have been obtained with the monthly values to describe the relation with El Nino/La Nina events. The correlation coefficients were computed with the monthly values with the significant level of 95\% for EP and WP over north and southern parts.

\section{Results and Discussion}

\subsection{Relationship between SW and SST Using Daily Data}

Figures 1(a)-(d) depicts the daily variation of the SST and SW located at $0^{\circ} \mathrm{N}$ $147^{\circ} \mathrm{E}, 2^{\circ} \mathrm{N} 147^{\circ} \mathrm{E}, 5^{\circ} \mathrm{N} 147^{\circ} \mathrm{E}, 8^{\circ} \mathrm{N} 147^{\circ} \mathrm{E}$ in a random day.

From the figures, one can see there is a lag between SWR and SST higher values. This indicates that after SWR reaches its maximum, sea surface gets more heat and attains its maximum at 2 hours. (Figure 1(a)) At the equator, the maximum value of SWR is about 800 , appeared at $1 \mathrm{pm}$, the maximum value of SST is about 30 , appeared at $3 \mathrm{pm}$, the two maximum value have a time lag of 2 hours. After attaining the highest value of the day, SW decreases sharply but SST changes slowly. (Figure 1 (b)) In the $2^{\circ} \mathrm{N}$, SWR maximum value occurs at 12 am
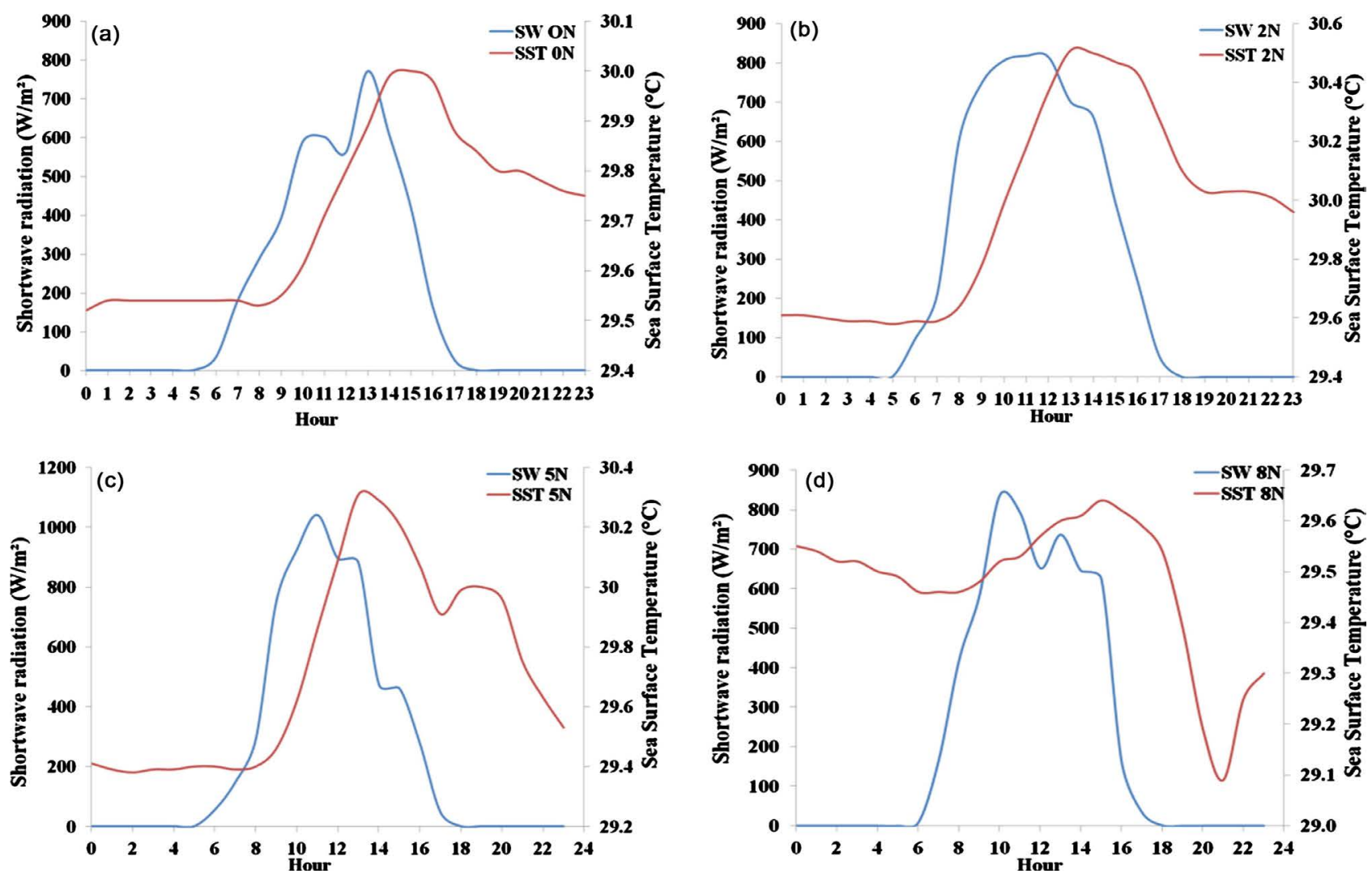

Figure 1. Diurnal variation of shortwave radiation and sea surface temperature randomly taken date at different latitudes (at equator, $2^{\circ} \mathrm{N}, 5^{\circ} \mathrm{N}$ and $8^{\circ} \mathrm{N}$ ) and at $147^{\circ} \mathrm{E}$ longitude. 
and persists for longer duration, the maximum value of SST appears at $1 \mathrm{pm}$, after that SST changes slowly, the lag is 1 hour. With the increase in latitude, the peak time forward one hour. (Figure $1(\mathrm{c})$ ) located in the $5^{\circ} \mathrm{N}$, SWR reaches its maximum of $1000 \mathrm{~W} / \mathrm{m}^{2}$, the maximum value of SST also increased to 30.4, highest SWR appears at 11 hours; SST appears at 13 hours, indicating a lag of 2 hours. (Figure $1(\mathrm{~d})$ ) located at the $8^{\circ} \mathrm{N}$, SWR attains its maximum of $800 \mathrm{~W} / \mathrm{m}^{2}$ and SST also dropped to below 30 . The highest values of SWR can be seen at 10 am instead of $12 \mathrm{pm}$, this may be due to clouding. However, SST is increasing with the amount of SWR coming to the sea surface and attains its maximum $29.8^{\circ} \mathrm{C}$ after a lag of five hours. When SWR attains its maximum, SST is showing a decreasing trend, this implies there is a rainfall occurred during the period, so SST decreased after that SST increased slowly. Around 1600 hours, SWR decreased rapidly and SST decreased slowly. When observing the daily variations, one can know clearly that SST increases with SWR and sea surface temperature increases, however SST decrease will be smaller when compared with SWR. The diurnal cycle of SST is particularly pronounced in the western Pacific warm pool where mean winds are very weak [10]. There was a positive correlation between SST and SW, meanwhile, with the increasing of latitude, the peak time of the SW also in advance, but SST did not significantly ahead of time. At the same time, with the increasing of latitude, SW and SST peak duration also in reducing. There is a time lag between SW high and SST high and SST high also depends on the latitude. Also due to the SW values, when the SWR is persistant for more hours, SST increase faster than normal atmospheric condition. However, SWR reducing due to cloud cover which is also having effect on SST increment.

\subsection{Monthly Relations between SWR and SST}

Monthly buoy data has been used to obtain the relation between SWR and SST in the west and east side of Pacific Ocean. Figure 2(a), depicts the variation of SWR and SST over the eastern Pacific Ocean. The SWR is a dominant component in the surface net heating [11]. From the figure one can clearly understand the SST variations are related with the SWR, however there are some deviations especially during the winter time. In the summer time we can observe the higher SWR and consecutive raise of SST. As it is the composite of northern, southern and equatorial values. EP have monthly temperature variations, when there is an El Nino event happened, the SWR is increasing and resulting higher temperature. However the global circulation changes and upwelling is not happening due to lower winds. So the SWR is having direct impact on increase in temperature, which resulting El Nino event. Over WP, there is a warm pool consisting. SWR is not strongly influencing the increment in SST due to higher SST. There is higher convection is happening, resulting to formation of cloud and higher water vapour, reducing the SWR over the equatorial region. Converging of trade winds is happening, which foorms as inter tropical convergence zone (ITCZ), which can be seen as a cloud clusters. Over the ITCZ, clouding is higher, so it is reducing 


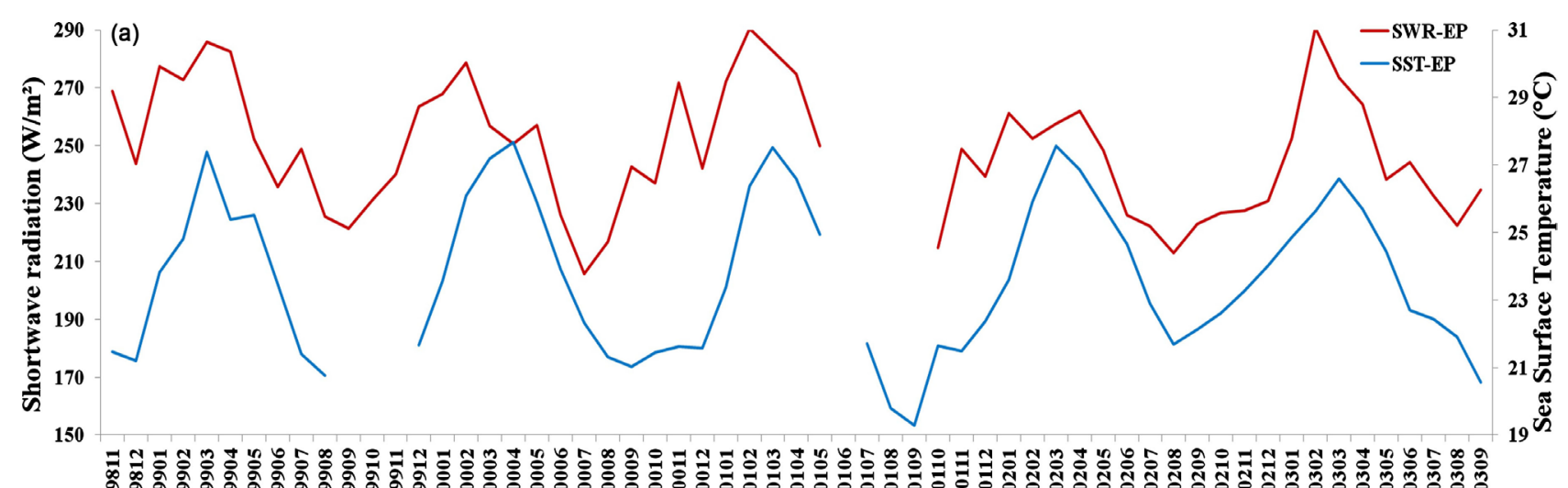

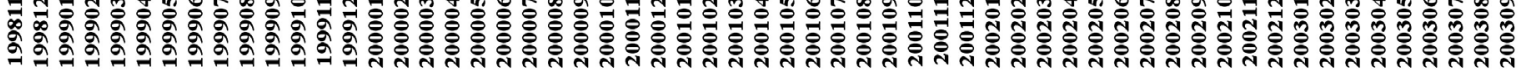

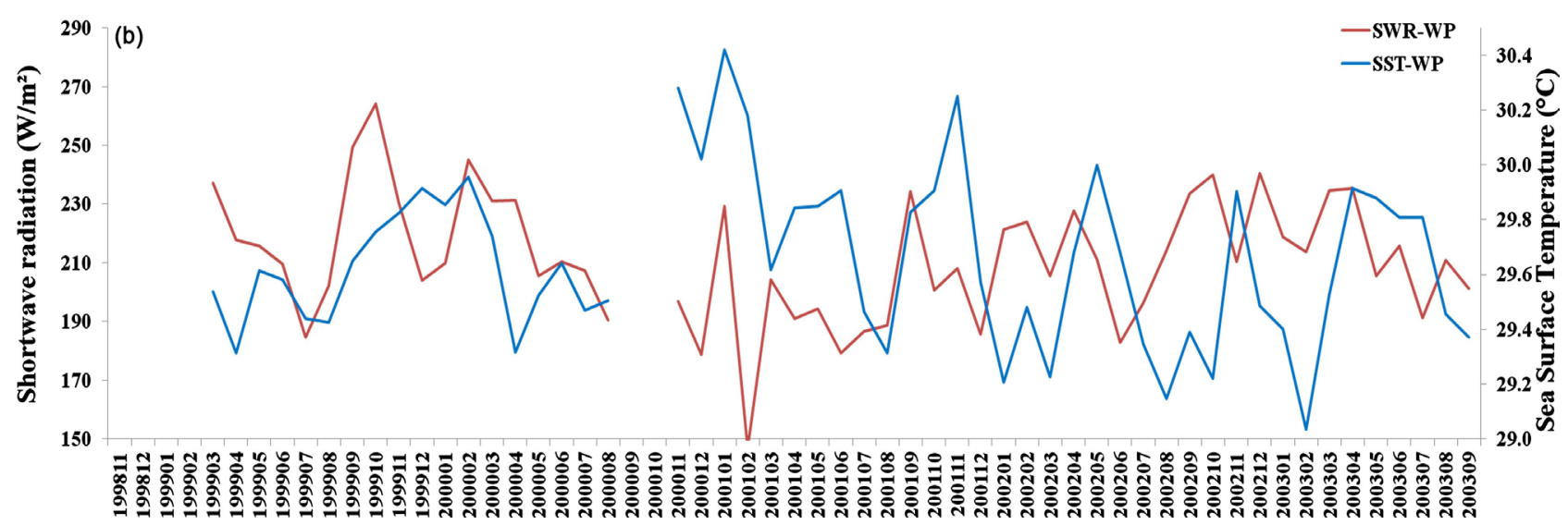

Figure 2. Mean monthly variations of shortwave radiation (SWR) and sea surface temperature (SST) over east (top) and west (bottom) Pacific Ocean during the study period.

the SWR. There is a transport of water happens to western pacific. When there is a convection happens, temperatures will reduce over the high SST zone. So there is no significant relation can be obtained over WP. EP SST variations are related with the general circulation and Southern Oscillation Index (ISO). Even SWR is higher, due to upwelling happening over the eastern pacific, SST is not increasing. When ENSO occurs, SWR is having direct influence on SST and higher temperatures can be seen. Over WP, SWR is not directly related. This is due to western pacific having warm pool, resulting the higher convection. When considering the SST, western pacific have higher mean temperature $\left(>29.5^{\circ} \mathrm{C}\right)$; however eastern pacific having mean temperature of $23.7^{\circ} \mathrm{C}$.

Variation of SWR and SST over WP are given in Figure 2(b). WP SWR illustrating lower SWR than eastern side, however SST is higher than eastern side. Equatorial currents carries the warm SST waters moves from the eastern part to western part along the equator and western part of Pacific Ocean attains warm waters especially in the northern part of WP. Due to Kuroshio Current warm SSTs moves to higher latitudes. Higher SWR can be found during the autumn season; however there are oscillations in other seasons too. When we compare the variations in SST, in the El Nino year SST values are lower and during the La Nina years SST is higher. In WP SSTs are higher, however it depends on El Ni- 
no/La Nina which alters the circulation pattern. WP prone to have higher number of tropical cyclone formation, clouding due to the tropical cyclones reduces the SWR. However, warmer SSTs $\left(>26.5^{\circ} \mathrm{C}\right)$ can generate the tropical cyclones.

We compared the relation between SWR and SST and the relation is shown in Figure 3.

From Figure 3, over WP-north the correlation between SST and SWR is 0.15, however in the WP-south there is a negative correlation $(\mathrm{CC}=-0.21)$. These correlations clearly indicating that, SST and SWR are not having a significant relation between them. However, when checking Figure 2, there is an oscillation can be observed between SST and SWR with a little lag between them. Over the EP-north, there is a strong positive correlation can be observed of 0.63 . This may be due to the cold water is coming from the northern pole due to circulation and SST is mainly depends on SWR. In the EP-South, there is a positive relation between SST and SWR, however the CC is 0.22 . The lower correlation indicates
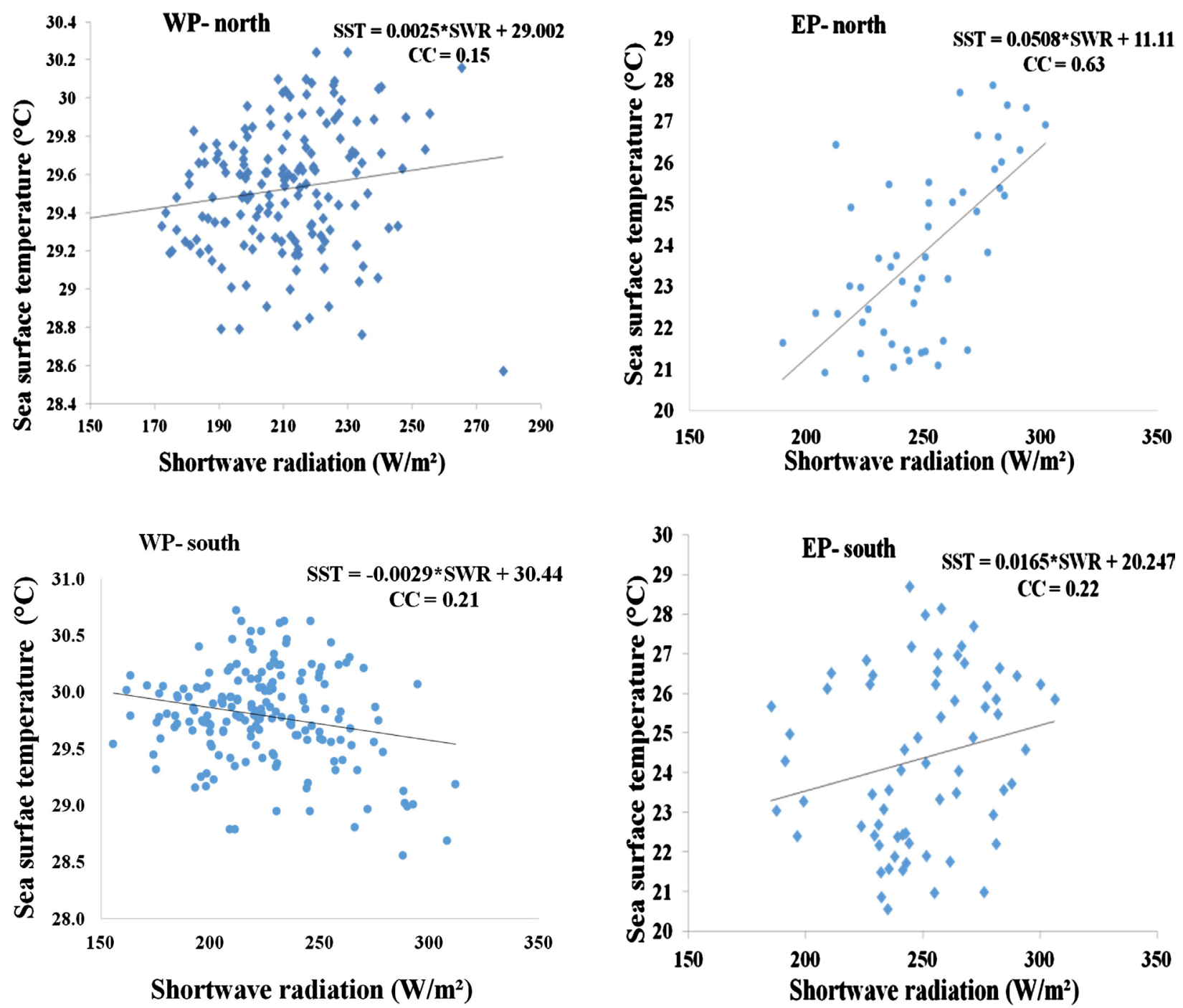

Figure 3. Scatter plots of sea surface temperature (SST) and shortwave radiation (SWR) over east and west Pacific Ocean. The correlation was calculated with the $95 \%$ significant level. 
that there is a strong upwelling occurs and SWR is not having a dominant role to control SST as it has been seen in the northern side. From this study one can tell northern hemispheric SWR is having influence on SST and there is a positive relation, however in the eastern side is more than western side. This may be due to in the eastern side there is no influence of landmass, however in the western side influence of landmass and also leading to warmer temperature due to land-sea interaction.

\subsection{East-West SWR and SST in Relation to El Nino/La Nina}

The annual variations between east and west SWR and SST are clearly seen from Figure 4(a) and Figure 4(b). It is well known that El Nino startes in the EP by collapsing upwelling and attains warmer SST. However, in recent years El Nino can be found from the central Pacific Ocean warming and higher SST anomalies in the central Pacific Ocean called as El Nino modiki [12]. In the study period, there is one El Nino event (2002) and one La Nina event (1999). During the El Nino year 2002, in the EP SST increased rapidly from 2001 September, reaches its peak on May 2002, however in the WP attains lower than normal temperatures. When compare SWR, in the EP it is increasing from October 2001 to April 2002 and in the WP SWR increased from November 2001 to April 2002 and then decreased. This clearly indicates that in the EP SWR is higher during the initiation of El Nino attaining higher SST. Normally El Nino commences during December month in the EP higher SWR leading to SST, however the circulation also changes during that time.

During the La Nina event in 1999-2000, EP SST increased up to March 1999 then decreased to its minimum in September 1999. As mentioned in the previous section, SST is showing its seasonal variability, during February month SST increased to its maximum. WP SST clearly showing the lower than normal in March 1999, then SST increased. When compare the WP and EP temperature difference, it is maximum. As if La Nina event occurs, the west and east temperatures will be maximum and the circulation will be stronger as is opposite of an El Nino event. SWR in EP is lower than normal and the relation with SST is
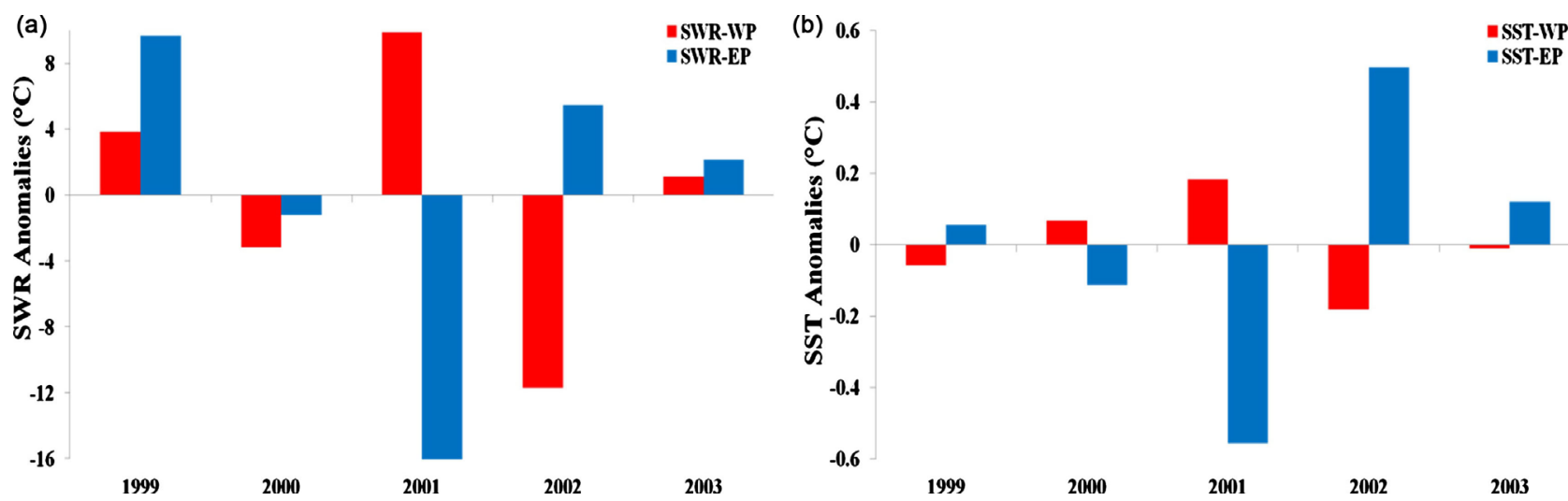

Figure 4. Annual variation of SWR (left pannel) and SST (right pannel) over the east and west Pacific Ocean during the study period. 
minimal. In the WP, higher SWR leading to increase in SST, however depends on seasonal.

\section{Conclusion}

From this study we can conclude that there is a time lag of $1-2$ hours between SWR and SST to attain the peak values, however, depending on latitude. In the EP, SWR and SST are following the seasonal variation. SST is mostly depends on the SWR and following the seasonal variations. WP SST is higher and there is no significant relation with SWR. This is due to warm pool over the western Pacific Ocean. Convection occurs over that region leading to cooling of SST which also reduces the SWR at the sea surface. During the ENSO, EP temperatures are increasing, which can be seen from the figures. This is also related with the SOI and global circulation. During El Nino event, higher SWR and SST can be observed in the EP and the influence of SWR is lower in WP. The SST difference in the El Nino is lower when compared with the La Nina. During La Nina the SST difference between WP and EP is higher. However SWR is higher (lower) in EP in La Nina (El Nino).

\section{Conflicts of Interest}

The authors declare no conflicts of interest regarding the publication of this paper.

\section{References}

[1] Trenberth, K.E. (1997) The Definition of El Niño. Bulletin of the American Meteorological Society, 78, 2771-2777. https://doi.org/10.1175/1520-0477(1997)078<2771:TDOENO>2.0.CO;2

[2] Trenberth, K.E. and Stepaniak, D.P. (2001) Indices of El Niño Evolution. Journal of Climate, 14, 1697-1701. https://doi.org/10.1175/1520-0442(2001)014<1697:LIOENO >2.0.CO;2

[3] Hanley, D.E., Bourassa, M.A., O’Brien, J.J., Smith, S.R. and Spade, E.R. (2003) A Quantitative Evaluation of ENSO Indices. Journal of Climate, 16, 1249-1258. https://doi.org/10.1175/1520-0442(2003)16<1249:AQEOEI >2.0.CO;2

[4] Kraus, E.B. and Turner, J.S. (1967) A One-Dimensional Model of the Seasonal Thermocline. II. The General Theory and Its Consequences. Tellus, 19, 98-106. https://doi.org/10.3402/tellusa.v19i1.9753

[5] Denman, K.L. (1973) A Time-Dependent Model of the Upper Ocean. Journal of Physical Oceanography, 3, 173-184. https://doi.org/10.1175/1520-0485(1973)003<0173:ATDMOT>2.0.CO;2

[6] Simpson, J.J. and Dickey, T.D. (1981) The Relationship between Downward Irradiance and Upper Ocean Structure. Journal of Physical Oceanography, 11, 309-323. https://doi.org/10.1175/1520-0485(1981)011<0309:TRBDIA>2.0.CO;2

[7] Woods, J.D. and Barkman, W. (1986) The Response of the Upper Ocean to Solar Heating. I: The Mixed Layer. Quarterly Journal of the Royal Meteorological Society, 112, 1-27. https://doi.org/10.1002/qj.49711247102

[8] Price, J.F., Weller, R.A. and Pinkel, R. (1986) Diurnal Cycling: Observations and 
Models of the Upper Ocean Response to Diurnal Heating, Cooling, and Wind Mixing. Journal of Geophysical Research, 91, 8411-8427. https://doi.org/10.1029/JC091iC07p08411

[9] Sui, C.-H., Li, X., Lau, K.-M. and Adamec, D. (1997) Multiscale Air-Sea Interactions during TOGA COARE. Monthly Weather Review, 125, 448-462. https://doi.org/10.1175/1520-0493(1997)125<0448:MASIDT>2.0.CO;2

[10] Weller, R.A. and Anderson, S.P. (1996) Surface Meteorology and Air-Sea Fluxes in the Western Equatorial Pacific Warm Pool during the TOGA Coupled Ocean Atmosphere Response Experiment. Journal of Climate, 9, 1959-1990. https://doi.org/10.1175/1520-0442(1996)009<1959:SMAASF $>2.0 . C O ; 2$

[11] Bond, N.A. and Cronin, M.F. (2008) Regional Weather Patterns during Periods of Anomalous Air-Sea Interactions at the Kuroshio Extension Observatory (KEO). Journal of Climate, 21, 1680-1697. https://doi.org/10.1175/2007JCLI1797.1

[12] Ashok, K., Behera, S.K., Rao, S.A., Weng, H. and Yamagata, T. (2007) El Niño Modoki and Its Possible Teleconnection. Journal of Geophysical Research, 112, 1-27. https://doi.org/10.1029/2006JC003798 